\title{
Paradigm shifts in terms of vascular emergencies during COVID-19 outbreak: An Expert Opinion report
}

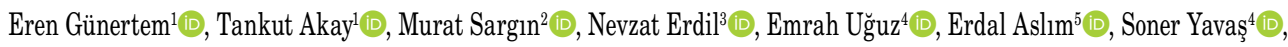

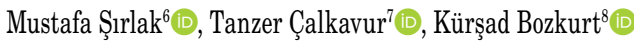 \\ ${ }^{1}$ Department of Cardiovascular Surgery, Başkent University Medical Faculty, Ankara, Turkey \\ ${ }^{2}$ Department of Cardiovascular Surgery, Siyami Ersek Thoracic and Cardiovascular Surgery Training and Research Hospital, Istanbul, Turkey \\ ${ }^{3}$ Department of Cardiovascular Surgery, Inonu University Medical Faculty, Malatya, Turkey \\ ${ }^{4}$ Department of Cardiovascular Surgery, Ankara City Hospital, Ankara, Turkey \\ ${ }^{5}$ Department of Vascular Surgery, Istinye University Medical Faculty, Istanbul, Turkey \\ ${ }^{6}$ Department of Cardiovascular Surgery, Ankara University Faculty of Medicine, Ankara, Turkey \\ ${ }^{7}$ Department of Cardiovascular Surgery, Ege University Faculty of Medicine, Izmir, Turkey \\ ${ }^{8}$ Department of Cardiovascular Surgery, Cerrahpaşa Medical Faculty, Istanbul, Turkey
}

\begin{abstract}
Coronavirus disease-2019 (COVID-19) has become a global threat. The entire population is now under the risk. Healthcare providers are concerned about handling an increased number of COVID-19 patients in limited capacities of facilities. Some therapies are being postponed indefinitely. Patients with vascular diseases usually have multiple comorbidities and, therefore, many of them are prone to infection. However, vascular surgical pathologies are usually related to progressive diseases. Postponement may not be possible for every patient in this group of patients. Thus, prioritization is crucial and a specialized algorithm is needed. In this review, we provide a succinct overview of arterial and venous emergencies and present a classification system and treatment algorithm on an individual basis.
\end{abstract}

Keywords: COVID-19, emergency treatment, pandemic, vascular surgical procedure.

Since the first case of severe acute respiratory syndrome-coronavirus-2 (SARS-CoV-2; COVID-19) was reported in late December 2019 in Wuhan province of China, the outbreak has spread to more than a million individuals around the world. The World Health Organization (WHO) has currently defined this outbreak as a pandemic. ${ }^{[1]}$ Since first case of COVID-19 was officially confirmed in Turkey on March $11^{\text {th }}, 2020$, the number of cases exceeded 100,000 and more than 2,000 deaths have been reported at the time of writing this article. Currently, the entire population is under the risk of COVID-19.

Patients with vascular diseases have usually multiple comorbidities and, therefore, many of them are prone to infection. In addition, these vascular comorbidities increase the mortality and morbidity rates in patients with COVID-19. Conversely, the incidence of thrombotic complications in the intensive care unit (ICU) patients with COVID-19 is higher and may worsen in the microvascular arterial circulation or cause venous thromboembolic events. When a surgical team decide to hospitalize a patient for a vascular intervention, they should also take into account that this patient may have been contacted with the virus before administration. Furthermore, this patient will be also under the risk of COVID-19 during hospitalization, which creates a real challenge for the vascular team during the perioperative period, while managing suspected or confirmed COVID-19 cases. It is indisputable that this pandemic will change how medicine is going to be practiced across the globe in the near future. It is also obvious that

Received: May 11, 2020 Accepted: May 11, 2020 Published online: May 18, 2020

Correspondence: Eren Günertem, MD. Başkent Üniversitesi Tıp Fakültesi Kalp ve Damar Cerrahisi Anabilim Dalı, 06490 Bahçelievler, Ankara, Türkiye. e-mail: gunertemeren@gmail.com 
a suspected/confirmed COVID-19 patient should be assessed by a specific algorithm for any kind of medical, interventional, or surgical treatment.

The major concern of healthcare providers is to handle the estimated high number of COVID-19 patients in limited capacities of facilities. Some treatments can be postponed indefinitely. However, vascular surgical pathologies are usually related to progressive diseases. The need of intervention and the type and timing of the intervention should be recognized by an experienced team who is expected to establish the risks which will be encountered with a delay. The risk to the patient and the healthcare workers should be also given full consideration. In the presence of non-deferrable operations, the potential exposure to both patient and staff must be prevented. The highest levels of preventive and precautionary measures must be taken by the healthcare facilities during the perioperative period.

In our routine practice, urgent/emergent procedures for vascular pathologies are welldefined by many authors. However, during the current outbreak, prioritization of the patients and procedures according to their clinical urgency may be challenging. Therefore, herein, we reviewed each arterial and venous emergencies under different topics and aimed to provide a succinct overview and to develop a classification system and a treatment algorithm according to patients' clinical status on an individual basis. We believe that this article will be a helpful guide for vascular surgeons to better prioritize their patients/procedures during COVID-19 outbreak.

\section{LOWER EXTREMITY ARTERIAL DISEASE}

Lower extremity arterial disease has several different presentations. Symptom severities may vary from one individual to another, regardless the extent and degree of disease progression. In symptomatic patients, the most typical presentation is intermittent claudication (IC). Chronic limb-threatening ischemia (CLTI) is characterized with ischemic rest pain. Tissue loss (ulcers, gangrene) or infection may be present. The former terminology of critical limb ischemia (CLI) refers that an urgent treatment is mandatory to avoid tissue or limb loss, as patients may lose their legs soon in the lack of revascularization. Critical limb ischemia may occur with the deterioration of the current chronic disease or due to an unconnected acute ischemic event.

\section{Intermittent claudication}

In routine practice, surgery or intervention indications for patients with IC are well-determined and defined as elective procedures. ${ }^{[2,3]}$ For this group of patients, only exercise therapy is effective and improves symptoms and quality of life with increased maximum walking distance. ${ }^{[4]}$ During the outbreak, patients with IC should be kept away from healthcare facilities. Routine follow-ups can be delayed as long as possible.

\section{Chronic limb-threatening ischemia}

Chronic limb-threatening ischemia is nearly never caused by isolated aortoiliac disease, unlikely to be interrelated with isolated superficial femoral artery lesions, usually femoropopliteal disease with or without aortoiliac or infrapopliteal disease is found. Under normal circumstances, revascularization should be attempted as much as possible. Minor or major amputations may be also needed to remove necrotic tissues or non-salvageable infectious lesions. However, all these therapeutic approaches should be postponed during COVID-19 pandemic, except for the presence of severe infectious findings (i.e., purulent discharge, deep tissue involvement, or systemic inflammatory response syndrome). In these patients, it is not always possible to achieve satisfying outcomes with revascularization. Urgent primary amputation should be the first choice rather than revascularization in this extraordinary era. The Wound, Ischemia, and Foot Infection (WIfI) classification system ${ }^{[5]}$ can be used to obtain a patient's risk of amputation or revascularization chance, which can guide the physician on how aggressive to be for limb salvage. Patients with critical limb ischemia and unsuitable conditions for revascularization may be hospitalized considering the conditions of hospital. One-week intravenous (IV) iloprost therapy may provide both symptomatic relief and improve outcomes.

\section{Acute limb ischemia}

Acute limb ischemia is related to sudden decrease in the arterial flow to the limb. Potential etiological factors include progressive disease, embolization, dissection, thrombosis, thrombosis of grafts or a popliteal aneurysm, popliteal entrapment syndrome, traumatic injury, phlegmasia cerulea dolens or iatrogenic. Limb salvage is risky and emergent/urgent management is inevitable. Surgical or interventional procedures should be performed to correct the underlying cause for limb salvage. In case of neurological deficit, emergent revascularization is indicated in all circumstances. ${ }^{[2]} \mathrm{A}$ clinical standardization for patients with acute limb 
Table 1. Clinical categories of acute limb ischemia according to Rutherford et al. ${ }^{[6]}$

\begin{tabular}{|c|c|c|c|c|c|}
\hline \multirow[b]{2}{*}{ Category } & \multirow[b]{2}{*}{ Description } & \multicolumn{2}{|c|}{ Findings } & \multicolumn{2}{|c|}{ Doppler signals } \\
\hline & & Sensory loss & Muscle weakness & Arterial & Venous \\
\hline 1. Viable & Not immediately threatened & None & None & + & + \\
\hline \multicolumn{6}{|l|}{ 2. Threatened } \\
\hline a. Marginally & Salvageable if promptly treated & Minimal & None & - & + \\
\hline b. Immediately & Salvageable with urgent revascularization & $\begin{array}{c}\text { More than toes } \\
\text { Rest pain + }\end{array}$ & Mild, moderate & - & + \\
\hline 3. Irreversible & Major tissue loss or permanent nerve damage & Anesthetic & Paralysis & - & + \\
\hline
\end{tabular}

ischemia created by Rutherford et al. ${ }^{[6]}$ in 1997 will be helpful to decide timing (Table 1). Accordingly, Grade IIb patients must be treated as soon as possible and revascularization should be performed within hours in Grade IIa patients. In the light of this finding, if there is a suspicion, tomographic evaluation for COVID-19 may be reasonable. Furthermore, for the rational use of hospital facilities such as beds or surgical equipment, Grade I and III patients can be treated in the outpatient setting.

\section{UPPER EXTREMITY ARTERIAL DISEASE}

Upper extremity artery disease related to atherosclerosis is usually located at the brachiocephalic trunk level or in the subclavian and axillary arteries. Revascularization is indicated according to patient's symptoms and its severity. In symptomatic patients with subclavian artery stenosis/occlusion, revascularization is indicated routinely. However, therapeutic managements in COVID-19 era should be similar to that for lower extremity arterial diseases. On the other hand, physicians can face with specific clinical manifestations for upper extremity arterial disease including occurrence of transient ischemic attack (TIA)/stroke due to steal syndrome, coronary subclavian steal syndrome, and hemodialysis access dysfunction on the same site. In such cases, treatment should be performed immediately.

\section{AORTOILIAC ANEURSYMAL AND OCCLUSIVE DISEASE}

Aortoiliac occlusive lesions are usually present with IC. Management of this disease should be organized as described previously for other occlusive arterial diseases. In brief, patients with salvageable acute limb ischemia should be treated immediately. Chronic conditions can be postponed indefinitely. Isolated iliac artery aneurysms comprise less than $2 \%$ of all intra- abdominal aneurysms. ${ }^{[7]}$ As stated in the European Society for Vascular Surgery (ESVS) 2019 Clinical Practice Guidelines on the Management of Abdominal Aorto-iliac Artery Aneurysms, ${ }^{[8]}$ a certain threshold for repair of asymptomatic iliac aneurysms is absent. An aneurysm larger than $>3.5 \mathrm{~cm}$ is associated with a high risk of rupture and mortality after occurrence of rupture, reaching up to $50 \%$ even with emergency treatment. ${ }^{[9]}$ Therefore, an urgent intervention is required for patients with iliac aneurysms larger than $3.5 \mathrm{~cm}$ even in the COVID-19 era. Ruptured aneurysms must be repaired as soon possible without any doubt.

\section{AORTIC DISEASES}

Aortic diseases contribute to the wide spectrum of arterial diseases including aortic aneurysms, aortic dissection (AD), intramural hematoma (IMH), penetrating atherosclerotic ulcer (PAU) and traumatic aortic injury (TAI), pseudoaneurysms, aortic rupture and atherosclerotic disease. Aortic diseases may be diagnosed after a long period and treated with elective surgical or interventional procedures. These procedures can be postponed during the COVID-19 pandemic. On the other hand, they may have an acute presentation and be life-threatening. In such cases, rapid diagnosis and decision-making strategies are necessary to reduce the extremely poor prognosis.

\section{Thoracic/abdominal aortic aneurysms}

Aneurysm is the second most common disease of the aorta. The Global Burden Disease 2010 project reported that the overall death rate from aortic aneurysms and AD reached to 2.78 per 100,000 inhabitants from 1990 to 2010 all over the world. ${ }^{[10]}$ On the other hand, the prevalence and incidence of abdominal aortic aneurysms have declined over the last two decades. ${ }^{[10,11]}$ Surgical or endovascular treatment is indicated in asymptomatic patients with an aorta of $>55 \mathrm{~mm} \cdot{ }^{[12]}$ The risk of rupture or dissection is lower 
in patients with an aorta below $55 \mathrm{~mm} \cdot{ }^{[13]}$ However, there is usually a prompt increase in the risk of lifethreatening complications, when the aortic diameter exceeds to $>60$ to $65 \mathrm{~mm}$. Pain may be present in patients with aortic aneurysms and rupture should be considered at first. ${ }^{[14]}$ In case of rupture, mortality can increase up to $54 \%$ at $6 \mathrm{~h}$ and $76 \%$ at $24 \mathrm{~h}$ after the first event. $^{[15]}$ To reduce the mortality rate, an emergent therapeutic approach should be performed in these cases. In addition, all symptomatic patients should be operated urgently, irrespective of the diameters due to the risk of rupture. ${ }^{[14]}$ One of other life-threatening pathologies of the aorta is a pseudoaneurysm. In patients with aortic pseudoaneurysms, irrespective of the size of the aneurysm, urgent interventional or open surgical procedures are always indicated due to the high risk of rupture. ${ }^{[12]}$

\section{Acute aortic syndromes}

Acute aortic syndromes (ASS) are defined as emergency conditions which includes AD, IMH, PAU, and TAI. The most feared and mortal type of AAS is AD. Patients with acute Type A AD have a two-fold higher mortality rate than those with Type $B$ $\operatorname{AD}\left(25 \%\right.$ and $12 \%$, respectively). ${ }^{[16]}$ Acute Type A AD patients suffer from a mortality of $50 \%$ within the first $48 \mathrm{~h}$, if left untreated, and emergent surgery is the only option, regardless the presence of the pandemic. In routine practice, patients with uncomplicated Type B AD are treated with medical therapy. If patients remain asymptomatic with drugs, they should be discharged as soon as possible, and the intervention can be scheduled after the outbreak. Nevertheless, Type B AD patients with persistent or recurrent pain, uncontrolled hypertension despite full medication, early aortic expansion, and malperfusion and signs of rupture are considered complicated and they have poor prognosis. ${ }^{[17]}$ In such cases, emergent treatment should be planned. Treatment of acute IMHs should be similar to the therapeutic management for AD. In the presence of PAU, it has been recommended that asymptomatic PAUs greater than $20 \mathrm{~mm}$ or with a neck of $>10 \mathrm{~mm}$ cause a higher risk of progression ${ }^{[18]}$ and may need an early intervention in the COVID-19 era. For other PAU patients, the intervention can be postponed, as well. In patients with TAI, the type of aortic injury is a critical factor in deciding the timing of intervention. Patients with rupture or large periaortic hematomas should be treated as emergency cases. For all other conditions, treatment can be delayed.

\section{ENDOLEAKS AND GRAFT INFECTIONS}

Endovascular aortic repair procedures such as thoracic endovascular aortic repair (TEVAR), endovascular aneurysm repair (EVAR), and chimney endovascular aortic repair (chEVAR) have been widely used all around the world. Endoleak is the most common complication after these procedures and it adversely affects the outcomes. Persistent flow into the aneurysm sac due to inadequate sealing of the stent graft on proximal (Type 1A) or distal (Type 1B) zone is dangerous and associated with a high rupture risk. Similar to Type 1 endoleaks, these endoleaks expose the aneurysm to direct aortic pressure with a subsequent risk of rupture. ${ }^{[19]}$ Type 1 and 3 endoleaks should be treated promptly during the outbreak. On the other hand, Type 2 endoleaks can resolve spontaneously and $<1 \%$ of these endoleaks resulted in a rupture. Of note, there is no consensus regarding when the intervention is indicated for Type 2 endoleaks. ${ }^{[20]}$ Re-intervention for Type 2 endoleak after endovascular abdominal aortic aneurysm repair should be considered in the presence of a significant aneurysm growth $(>1 \mathrm{~cm})$. Otherwise, Type 2 endoleak repair must be postponed in the COVID-19 era. In the literature, no cases of rupture due to Type 4 endoleak have been described yet. ${ }^{[19]}$

Vascular graft infection occur in 4 to $6 \%$ of peripheral grafts and 1 to $3 \%$ of aortic grafts, leading to a considerable increase in the mortality rates. ${ }^{[21]} \mathrm{It}$ causes stenosis, graft migration, endoleak, cellulitis, and enteric or cutaneous fistulas and also manifest itself with systemic inflammatory response syndrome or life-threatening septic shock. Samson et al. ${ }^{[22]}$

Table 2. Samson's classification for vascular graft infections ${ }^{[22]}$

\begin{tabular}{ll}
\hline Samson's classification & Definition \\
\hline Group 1 & Infection extends no deeper than dermis \\
Group 2 & Infection involves subcutaneous tissue but does not come into direct contact with the graft \\
Group 3 & Infection involves body of the graft but not an anastomosis \\
Group 4 & Infections surround an exposed anastomosis but bacteremia or bleeding has not occurred \\
Group 5 & Infections involve an anastomosis and are associated with septicemia and bleeding \\
\hline
\end{tabular}


developed a classification system for vascular graft infections. During the outbreak, this classification can be helpful for physicians to plan treatment strategies (Table 2). According to the Samson's classification, for Group 5 patients, an urgent surgery must be performed. Patients in Group 4 may be discussed individually. Surgical procedures for Group 1-3 patients can be postponed and outpatient treatment may be reasonable for these patients. Besides that, the occurrence of acute limb ischemia due the graft infection should be an urgent surgery indication.

\section{MESENTERIC ARTERY DISEASE}

\section{Acute mesenteric ischemia}

Acute occlusion of the superior mesenteric artery is more often related to embolism and usually requires immediate revascularization to survive. Patients present with severe abdominal pain with minimal findings at examination, vomiting and diarrhea. Although it is controversial, emergent revascularization should be the first attempt instead of bowel resection, unless there is serious peritonitis and septic shock. ${ }^{[2]}$

\section{Chronic mesenteric artery disease}

Chronic mesenteric artery disease refers stenosis or chronic occlusion. Symptoms of chronic ischemia include postprandial abdominal pain, weight loss, diarrhea, or constipation. Asymptomatic patients do not need any prophylactic revascularization. However, in symptomatic patients, it is not recommended to delay revascularization, as delayed revascularization has been shown to be associated with clinical deterioration. ${ }^{[2]}$ During these COVID-19 days, urgent revascularization should be performed for symptomatic patients as recommended in daily practice.

\section{CAROTID ARTERY DISEASE}

Carotid artery stenosis (CAS) is associated with a remarkably high risk of stroke or TIA. ${ }^{[23]}$ Carotid endarterectomy (CEA) or stenting are the primary treatment choices for prevention. However, current evidence for the optimal timing of the intervention is still limited. In a recent study, the Carotid Alarm Study demonstrated that CEA performed within $48 \mathrm{~h}$ was associated with a higher risk of complications compared to surgery performed $48 \mathrm{~h} 14$ days after the most recent ischemic event. ${ }^{[24]}$ In accordance with this recent and large-scale population study, emergent procedures are not mandatory and symptomatic patients with CAS can be treated at least two week after the most recent ischemic event during the pandemic. This strategy also gives the physician a chance to screen CAS patients preoperatively in case of an infection suspicion. In asymptomatic patients, decision should be made on an individual basis. The degree of stenosis, plaque morphology/motion, and presence of contralateral lesion should be taken into account during prioritization process.

Aneurysms of the extracranial carotid artery are rare entities. However, they can be responsible for severe complications such as rupture, thrombosis, or embolism. There is still no consensus among the researchers regarding indications for any intervention. Therefore, all procedures to treat extracranial carotid artery aneurysms should be delayed, as long as the patient is asymptomatic. During the COVID-19 pandemic, regional or local anesthesia is recommended in almost all surgical procedures to shorten hospitalization duration and for the prudent use of facilities. Nevertheless, regional anesthesia may lead to increased coughing in patients undergoing carotid surgery and it may not be feasible, as it increases the risk of virus spread.

\section{VENOUS DISEASE}

\section{Deep vein thrombosis (DVT)}

The lifetime incidence of DVT varies between 2.5 and 5\%. ${ }^{[25]}$ Outpatients diagnosed with acute DVT during the outbreak should be treated at home in the first place to use healthcare facilities rationally and not getting patients under the risk of COVID-19. The preference of hospitalization should be left to the physician, according to comorbidities and COVID-19 risk factors of the patient. Low-molecular-weight heparin (LMWH) or direct oral anticoagulants (DOACs) are the first choice for anticoagulant therapy during medical treatment to prevent patients from admission to health institutions for international normalized ratio monitoring. It would be also appropriate not to prefer interventional treatment methods for the same precautionary reasons. Thus, there is still no consensus about the superiority of endovascular approaches. Percutaneous options may be considered only in hospitalized patients with a low risk of bleeding, such as age less than 65 years, absence of cancer history, and absence of recent trauma or surgery. Also, the placement of a temporary inferior vena cava (IVC) filter can be a feasible option to prevent venous thromboembolism (VTE). 


\section{Phlegmasia cerulea dolens}

Phlegmasia cerulea dolens is a distinct clinical entity and occurs when the occlusion of caval or lower extremity DVT increases the venous pressure sufficient to occlude the arterial inflow. It is a limbthreatening scenario. In the presence of phlegmasia cerulea dolens, patients are needed be hospitalized and immediate elimination of all thrombi to reduce swelling and restore arterial perfusion is required. ${ }^{[26]}$ Urgent endovascular therapy should be considered in these patients, even in pandemic.

\section{Venous thromboembolism}

Hospitalized patients diagnosed with COVID-19 have a higher risk of developing DVT/VTE. In a recent study, the incidence of thrombotic complications in the ICU patients with COVID-19 was estimated as $31 \%$, which is a remarkably high rate. ${ }^{[27]}$ In such cases, thromboprophylaxis and treatment approaches are vital. Recommendations of our society have been recently published. ${ }^{[28]}$ In addition, development of VTE may worsen respiratory functions in COVID-19 and untreated VTE may adversely affect the outcomes. Therefore, it is of utmost importance to initiate treatment as soon as possible in hospitalized COVID-19 patients with VTE. In particular for hemodynamically unstable patients, systemic thrombolysis is recommended, if there is no contraindication. Catheter-directed thrombolysis should be considered in the availability of favorable facility conditions. Surgical pulmonary embolectomy may be a considerable option in experienced centers, when thrombolysis has failed. If the patient is hemodynamically stable, systemic or catheter-directed thrombolysis are not extremely urgent. However, they may be reasonable precautionary options in case of underlying respiratory distress related to COVID-19. This approach can preclude undesired deteriorations.

\section{Chronic venous ulcers}

Venous ulcer is a severe condition of chronic venous insufficiency (CVI) or post-thrombotic syndrome. About $70 \%$ of chronic ulcers of the lower limbs are caused by venous pathologies and do not heal within 6 weeks. ${ }^{[29]}$ Such patients should be treated with a multidisciplinary approach in routine practice. The main goals are the wound care, debridement, and treatment of the underlying venous pathology. However, during the COVID-19 era, these procedures should be postponed and routine controls of patients should be delayed. On the other hand, if there is a suspicion of bacterial infection with associated cellulitis or lymphangitis (i.e., erythema, edema, exudative discharge or increased local temperature), treatment with systemic IV antibiotics, urgent debridement, and perforator vein ablation may be needed.

\section{Chronic venous insufficiency}

All curative or cosmetic procedures must be postponed without any doubt in the COVID-19 pandemic. Indeed, bleeding varicose veins can be a health threat and may be sometimes difficult to stop without a professional approach. In the presence of massive bleeding, prompt treatment should be needed. Clot dressings or compression with bandages may not be always enough. Small-diameter varicose veins can be controlled effectively using sclerosing techniques and larger veins can be managed with operative removal. However, it is possible to perform these interventions on bedside in emergency rooms under local anesthesia which eliminates the need for hospitalization. During the outbreak, it appears to be a reasonable approach.

\section{TRAUMATIC/IATROGENIC VASCULAR INJURIES}

Traumatic or iatrogenic vascular injuries are usually life-threatening conditions. As such, thoracic aortic injury is the second most frequent cause of death after brain injury following a blunt trauma. The clinical presentation of vascular injury patients ranges from minor non-specific symptoms to hemodynamic shock. The rupture of vessels or dissections can be fatal and an urgent or emergent approach is always indicated. However, sometimes, in case of self-limiting bleeding or localized uncomplicated dissection, patients may be hemodynamically stable and timing of the procedure should be determined according to the pandemic-related conditions.

Few changes in the diagnosis and treatment algorithm may be reasonable during the COVID-19 era. Computed tomography $(\mathrm{CT})$ scan is a fast and easy tool with a sensitivity and specificity close to $100 \%$ for many vascular injuries, and COVID-19-specific lesions can be screened at same time. Therefore, it should be the first diagnostic tool instead of other options. Also, in a suitable anatomy, endovascular treatment modalities should be preferred rather than open surgery. By this way, local anesthesia can be performed in eligible patients to prevent exposure and hospitalization duration can be shortened.

Venous injuries are often self-limiting and not always require an intervention. Patients with a venous injury should be discharged as soon as possible 
after ensuring that there is no continuous bleeding. Furthermore, in case of localized arterial dissection or Type B AD without complication, patients can be followed with medical treatment and they should not stay at the healthcare center very long in these pandemic days.

\section{VASCULAR INVOLVEMENT IN ONCOLOGICAL PATIENTS}

Although the magnitude of this risk is not yet known, early reports suggest a substantial increased risk of death associated with COVID-19 infection among patients with cancer. In this era, postponing surgery and administering neoadjuvant therapy as a bridge therapy is recommended to reduce the risk to the patient and to preserve healthcare resources. ${ }^{[30]}$ However, malignancies can be associated with vascular involvement. A venous tumor thrombus including the IVC in patients with hepatocellular or renal carcinomas is one of the most common conditions. Tumor thrombus can also extend into the right atrium and becomes a life-threatening situation. ${ }^{[31]}$ The presence of a tumor thrombus with possible associated venous congestion and downstream thrombosis adds urgency to the management of these patients to achieve a better prognosis. In case of malignancy, arterial occlusions may occur due to tumor compression, direct arterial invasion, or embolization of thrombus and threaten perfusion. Although there is an underlying oncological disease, acute arterial occlusion is a surgical emergency and cannot be postponed, even in pandemic. Besides, in case of malignancy-specific situations such as carotid blowout syndrome, which is related to radiation therapy and causes massive acute hemorrhage, emergent surgery is needed to reduce mortality and neurological morbidity.

\section{VASCULAR ACCESS AND RELATED COMPLICATIONS}

Vascular access plays an essential role for hemodialysis treatment in patients with end-stage renal disease. Surgeons may experience difficulties about scheduling for the placement or repair of arteriovenous fistulas (AVFs) and IV catheters during pandemic. It is obvious that we cannot talk about elective interventions in this area. Nearly all interventions for vascular access are urgent. Additionally, complications related to vascular access can be life-threatening or cause serious morbidities and needed to be treated emergently. In the light of these data, before making recommendations, we divided patients into two groups as pre-hemodialysis patients and chronic hemodialysis patients. For pre-hemodialysis patients, in the presence of appropriate arterial and venous structure as documented by ultrasound, the placement of an AVF should be performed under local anesthesia. Patients can be discharged on the same day, when a good thrill is obtained. If vascular structures are not suitable for AVF, ultrasound-guided permanent-tunneled IV catheter placement is recommended. Temporary catheters seem to be an easy option, although their complications rates are noteworthy. Chronic hemodialysis patients are under the thrombosis risk of AVFs or IV catheters. Thrombosis may cause AVF malfunction and induce embolic/ischemic events. In both scenarios, urgent interventions are mandatory. Endovascular approaches may be the first choice. Another important issue related to the vascular access is infection. In case of an advanced infectious condition (i.e., ulcers with purulent discharge, cutaneous fistula, or septic events), an emergent intervention must be performed. Furthermore, patients with a pseudoaneurysm and/or ruptured aneurysm are under life-threatening situations and emergent surgery is needed. Surgical treatment of uncomplicated aneurysms can be postponed in this COVID-19 era.

\section{Determination of patients' status}

In daily practice, balancing between the patient care and optimal utilization of resources is mandatory. During the COVID-19 outbreak, scheduling of patients and procedures according to their clinical urgency is crucial for many reasons as mentioned previously in this paper. To achieve better results for both patients or healthcare providers and use existing healthcare resources more efficiently, physicians should use a priority algorithm for patients with vascular disease. Determination of patients' urgency should be the first step.

In March 2020, the American College of Surgeons released an online guideline regarding case triage during the COVID-19 era. ${ }^{[32]}$ The authors prioritized surgical procedures according to their emergencies (Table 3).

As the Turkish National Vascular and Endovascular Surgery Society, we also divided patients into three status according to the most frequently encountered vascular pathologies (Table 4). Based on this classification, Status A patients includes emergent and salvage cases and they should be operated as soon as possible with protective measures. Status B patients refer urgent and optional cases, indicating that the physician can postpone the intervention regarding 
Table 3. The American College of Surgeons - Elective Case Triage Guidelines for Vascular Surgical Care ${ }^{[32]}$

\begin{tabular}{|c|c|c|}
\hline Category & Condition & Tier class \\
\hline AAA & $\begin{array}{l}\text { Ruptured or symptomatic TAAA or AAA } \\
\text { Aneurysm associated w/infection or prosthetic graft infection } \\
\text { AAA }>6.5 \mathrm{~cm} \\
\text { TAAA }>6.5 \mathrm{~cm} \\
\text { AAA }<6.5 \mathrm{~cm}\end{array}$ & $\begin{array}{l}3 \text { Do not postpone } \\
3 \text { Do not postpone } \\
2 \text { b Postpone if possible } \\
2 b \text { Postpone if possible } \\
1 \text { Postpone }\end{array}$ \\
\hline Aneurysm peripheral & $\begin{array}{l}\text { Peripheral aneurysm, symptomatic } \\
\text { Peripheral aneurysm, asymptomatic } \\
\text { Pseudoaneurysm repair: Not candidate for thrombin injection or compression, rapidly expanding, complex } \\
\text { Symptomatic non-aortic intra-abdominal aneurysm } \\
\text { Asymptomatic non-aortic intra-abdominal aneurysm }\end{array}$ & $\begin{array}{l}3 \text { Do not postpone } \\
\text { 2a Consider postponing } \\
3 \text { Do not postpone } \\
3 \text { Do not postpone } \\
\text { 2a Consider postponing }\end{array}$ \\
\hline Aortic dissection & Acute aortic dissection with rupture or malperfusion & 3 Do not postpone \\
\hline Aortic emergency & AEF with septic/hemorrhagic shock, or signs of impending rupture & 3 Do not postpone \\
\hline Bypass graft complications & $\begin{array}{l}\text { Infected arterial prosthesis without overt sepsis, or hemorrhagic shock, or impending rupture } \\
\text { Revascularization for high grade restenosis of previous intervention } \\
\text { Asymptomatic bypass graft/stent restenosis }\end{array}$ & $\begin{array}{l}3 \text { Do not postpone } \\
2 b \text { Postpone if possible } \\
1 \text { Postpone }\end{array}$ \\
\hline Carotid & $\begin{array}{l}\text { Symptomatic carotid stenosis: CEA and TCAR } \\
\text { Asymptomatic carotid artery stenosis }\end{array}$ & $\begin{array}{l}3 \text { Do not postpone } \\
1 \text { Postpone }\end{array}$ \\
\hline Dialysis & $\begin{array}{l}\text { Thrombosed or nonfunctional dialysis access } \\
\text { Infected dialysis access } \\
\text { Fistula revision for ulceration } \\
\text { Renal failure with need for dialysis access } \\
\text { Tunneled dialysis catheter } \\
\text { Fistula revision for malfunction/steal } \\
\text { Fistulagram for malfunction } \\
\text { Arteriovenous fistula and graft placement for dialysis (ESRD, CK4, and CK5 only) }\end{array}$ & $\begin{array}{l}3 \text { Do not postpone } \\
3 \text { Do not postpone } \\
3 \text { Do not postpone } \\
3 \text { Do not postpone } \\
3 \text { Do not postpone } \\
\text { 2b Postpone if possible } \\
\text { 2b Postpone if possible } \\
\text { 2a Consider postponing }\end{array}$ \\
\hline Mesenteric & $\begin{array}{l}\text { Symptomatic acute mesenteric occlusive disease } \\
\text { Chronic mesenteric ischemia }\end{array}$ & $\begin{array}{l}3 \text { Do not postpone } \\
2 b \text { Postpone if possible }\end{array}$ \\
\hline Peripheral vascular disease & $\begin{array}{l}\text { Acute limb ischemia } \\
\text { Limb ischemia: Progressive tissue loss, acute limb ischemia, wet gangrene, ascending cellulitis } \\
\text { Fasciotomy for compartment syndrome } \\
\text { Peripheral vascular disease: Chronic limb threatening ischemia - rest pain or tissue loss } \\
\text { Peripheral angiograms and endovascular therapy for claudication } \\
\text { Surgical procedures for claudication }\end{array}$ & $\begin{array}{l}3 \text { Do not postpone } \\
3 \text { Do not postpone } \\
3 \text { Do not postpone } \\
2 \text { b Postpone if possible } \\
1 \text { Postpone } \\
1 \text { Postpone }\end{array}$ \\
\hline Thrombolysis & Lysis, arterial and venous & $2 \mathrm{~b}$ Postpone if possible \\
\hline Torasik outlet syndrome & $\begin{array}{l}\text { Symptomatic venous torasik outlet syndrome with acute occlusion and marked swelling } \\
\text { Thoracic outlet syndrome, arterial with thrombosis } \\
\text { Thoracic outlet syndrome, neurogenic } \\
\text { Thoracic outlet syndrome, venous otherwise }\end{array}$ & $\begin{array}{l}\text { 2b Postpone if possible } \\
2 \mathrm{~b} \text { Postpone if possible } \\
1 \text { Postpone } \\
\text { 2a Consider postponing }\end{array}$ \\
\hline Trauma & Traumatic injury with hemorrhage and/or ischemia & 3 Do not postpone \\
\hline Venous & $\begin{array}{l}\text { Acute iliofemoral DVT with phlegmasia } \\
\text { Inferior vena cava filter placement } \\
\text { Massive symptomatic iliofemoral DVT in low risk patient } \\
\text { Procedures for ulcerations secondary to venous disease } \\
\text { Asymptomatic May-Thurner syndrome } \\
\text { Inferior vena cava filter removal } \\
\text { Varicose veins, GSV ablations }\end{array}$ & $\begin{array}{l}\text { 3 Do not postpone } \\
2 \mathrm{~b} \text { Postpone if possible } \\
\text { 2b Postpone if possible } \\
\text { 2a Consider postponing } \\
1 \text { Postpone } \\
1 \text { Postpone } \\
1 \text { Postpone }\end{array}$ \\
\hline Wounds/gangrene/amputation & $\begin{array}{l}\text { Amputations for infection/necrosis (TMA, BKA, AKA) } \\
\text { Lower extremity disease with non-salvageable limb (amputation) } \\
\text { Deep debridement of surgical wound infection or necrosis } \\
\text { Wounds requiring skin grafts } \\
\text { Amputations for infection/necrosis (toes) }\end{array}$ & $\begin{array}{l}3 \text { Do not postpone } \\
3 \text { Do not postpone } \\
2 b \text { Postpone if possible } \\
2 \mathrm{~b} \text { Postpone if possible } \\
2 \mathrm{~b} \text { Postpone if possible }\end{array}$ \\
\hline Spine & ALIF exposure for spine team & 2a Consider postponing \\
\hline Other & $\begin{array}{l}\text { Surgery/embolization for uncontrolled bleeding in unstable patients } \\
\text { Surgery/embolization for bleeding in stable patients } \\
\text { Mediport for immediate infusion needs } \\
\text { Port removal for complication }\end{array}$ & $\begin{array}{l}3 \text { Do not postpone } \\
2 b \text { Postpone if possible } \\
2 b \text { Postpone if possible } \\
2 b \text { Postpone if possible }\end{array}$ \\
\hline
\end{tabular}

AAA: Abdominal aortic aneursym; TAAA: Thoracoabdominal aortic aneursym; CEA: Carotid endarterectomy; TCAR: Transcarotid artery disease; ESRD: End-stage renal disease; CK: Chronic kidney disease; DVT: Deep vein thrombosis; TMA: Transmetatarsal; BKA: Below knee amputation; AKA: Above knee amputation; ALIF: Anterior lumbar interbody fusion; AEF: Aortoenteric fistula; GSV: Great saphenous vein. 
the patient's infectious status or the capacity of the clinic and availability of the healthcare equipment. In such cases, non-interventional options may be also beneficial. In confirmed and hospitalized COVID-19 patients, an intervention may be performed earlier, even if they are in the Status B. The decision should be at the discretion of the treating physician. For this group of patients, the decision should not be made upon COVID-associated risks. Capacity of the healthcare facility, work volume for the staff, and adequacy of the surgical/anesthesia equipment and availability of the blood and blood products should be taken into account by the physician during decision-making process. Nowadays, teleconference with mobile communication devices has been widely used. Status B patients can report changes in their clinical conditions or send pictures of diseased limbs to their physician through scheduled conversations. Thus, when an urgency arises, the patient can be referred to the hospital without any delay. Status C patients are elective cases and the intervention should be postponed as much as possible (Figure 1).

In the accordance of this classification, we recommend the following algortihm (Figure 2) for patients with vascular disease during outbreak.

\section{Choice of treatment modality: Open surgery or endovascular procedures?}

Currently, numerous emergent/urgent vascular diseases can be treated through endovascular approaches. ${ }^{[33-35]}$ The results obtained in a considerable of well-designed studies are comparable with open surgery. As endovascular procedures are less invasive, patients spend shorter time in the hospital after the intervention, which is a crucial issue to reduce bed occupation during the outbreak. In addition, direct contact between physicians and patients can be minimized by these procedures. Moreover, many of endovascular treatment modalities can be performed under local or regional anesthesia instead of general anesthesia which give physicians certain advantages to protect patients and themselves from virus. ${ }^{[36]}$ Although debates are still ongoing, indications for endovascular procedures, advantages or disadvantages over open surgery are well-defined by our national guideline both for arterial and venous diseases. ${ }^{[37]}$ During the outbreak, it may be permissible to go a little bit further beyond the guidelines. For instance, even surgical revascularization with a good-quality saphenous vein is recommended as the first-line treatment for patients with infrapopliteal arterial disease, endovascular modalities can take the front
Table 4. Prioritization of patients according to existing vascular pathologies

Status A patient

- Traumatic vascular injury (In presence of hemorrhage or ischemia)

- TAAA/AAA with rupture

- Acute type A aortic dissection

- Complicated type B aortic dissection

- Acute/critical limb ischemia (independent to etiology)

- Peripheral aneurysm with rupture

- Compartment syndrome (Fasciotomy)

- Carotid stenosis (in the presence of "String sign")

- Infected vascular prosthesis/catheters with ischemia, rupture or septic complications

- Acute mesenteric ischemia

- Phlegmasia cerulea dolens

- Acute PTE with RV failure or hemodynamic unstability

Status B patients

- Traumatic vascular injury (self-limited)

- Infected or necrotic non-salvageable limbs (Amputation)

- Complicated AVFs or other dialysis accesses

- Infected vascular prosthesis without ischemia, rupture or septic complications

- Large TAAA/AAA diameter $(>6.5 \mathrm{~cm})$

- Symptomatic TAAA/AAA

- Type 1 and 3 endoleaks

- Peripheral arterial aneurysm with recurrent embolic events (without ishemia)

- Peripheral pseudoaneursym

- Chronic limb ischemia with rest pain

- Severe carotid artery stenosis (According to plaque morphology)

- Symptomatic chronic mesenteric ischemia

- Acute iliofemoral DVT (without phlegmasia cerulea dolens)

- Acute PTE without RV Failure or hemodynamic unstability

- IVC tumors

- IVC filter placement

- Acquired AVFs with heart failure symptoms

- Port removal for complication

\section{Status C patients}

- Patients with intermittent claudication

- Chronic limb ischemia (without rest pain)

- Uncomplicated type B aortic dissection

- Asymptomatic graft or stent restenosis

- Chronic venous insufficiency/ulcers

- Asymptomatic iliocaval stenosis

- Pelvic congestion syndrome

- IVC filter removal

- Acquired AVFs without heart failure symptoms

- TAAA/AAA $<6.5 \mathrm{~cm}$

TAAA: Thoracoabdominal aortic aneurysm; AAA: Abdominal aortic aneurysm; PTE: Pulmonary thromboembolism; RV: Right ventricle; AVF: Arteriovenous fistula; DVT: Deep vein thrombosis; IVC: Inferior vena cava.

place in the algorithms during the pandemic. Briefly, in this extraordinary era, it is reasonable to indicate endovascular procedures in the first place for each eligible Status A or B patient to limit the spread of COVID-19. 


\begin{tabular}{|l|l|l|}
\hline Status A & "Operate immediately" & Intervention is required within $24 \mathrm{~h}$ \\
\hline Status B & "Follow and decide" & Intervention can be required within 30 days \\
\hline Status C & "Wait as long as possible" & Intervention can be performed after 30 days or postponed \\
\hline
\end{tabular}

Figure 1. Recommendations according to patient status.

\section{Preparation for surgery or interventional procedures}

In the presence of a condition which requires open surgery or endovascular procedure, the highest level of preventive and precautionary measures must be taken to ensure the patient and staff safety. An operation/ intervention room for the suspected/confirmed COVID-19 patients can be separated from others to prevent nosocomial transmission. Instruments and anesthetic equipment should be reserved specifically for these patients. The workflow of the COVID-19 operation room was well-defined by Chen et al. ${ }^{[36]}$ which included the routine universal infection prevention measures, the use of personal protective equipment, and decontamination procedure after the intervention. A strict anesthesia management protocol with infection control procedures should be performed for the suspected/confirmed COVID-19 patients. ${ }^{[38-39]}$ We recommend local or regional anesthesia instead of general anesthesia in eligible patients.

\section{Routine COVID-19 screening for patients with vascular urgency}

Moderate SARS-CoV-2 viral loads can be detected in nasal swabs in asymptomatic individuals. ${ }^{[40]}$ Additionally, CT is a valuable tool in screening and detecting patients with COVID-19 pneumonia, particularly in asymptomatic cases with a high suspicion index. ${ }^{[4]]}$ Therefore, it seems to be reasonable to screen COVID-19 suspected Status B patients with thoracic $\mathrm{CT}$ additionally to angiography protocol. In case of any suspicious findings, a nasopharyngeal swab can be collected and, then, the decision-making process should be based on the test results. This approach is also likely to decrease the exposure risk for workers and other individuals in the healthcare facility.

\section{Measures for postoperative period}

During the postoperative period of COVID-19 patients, a joint experienced COVID-19 team including

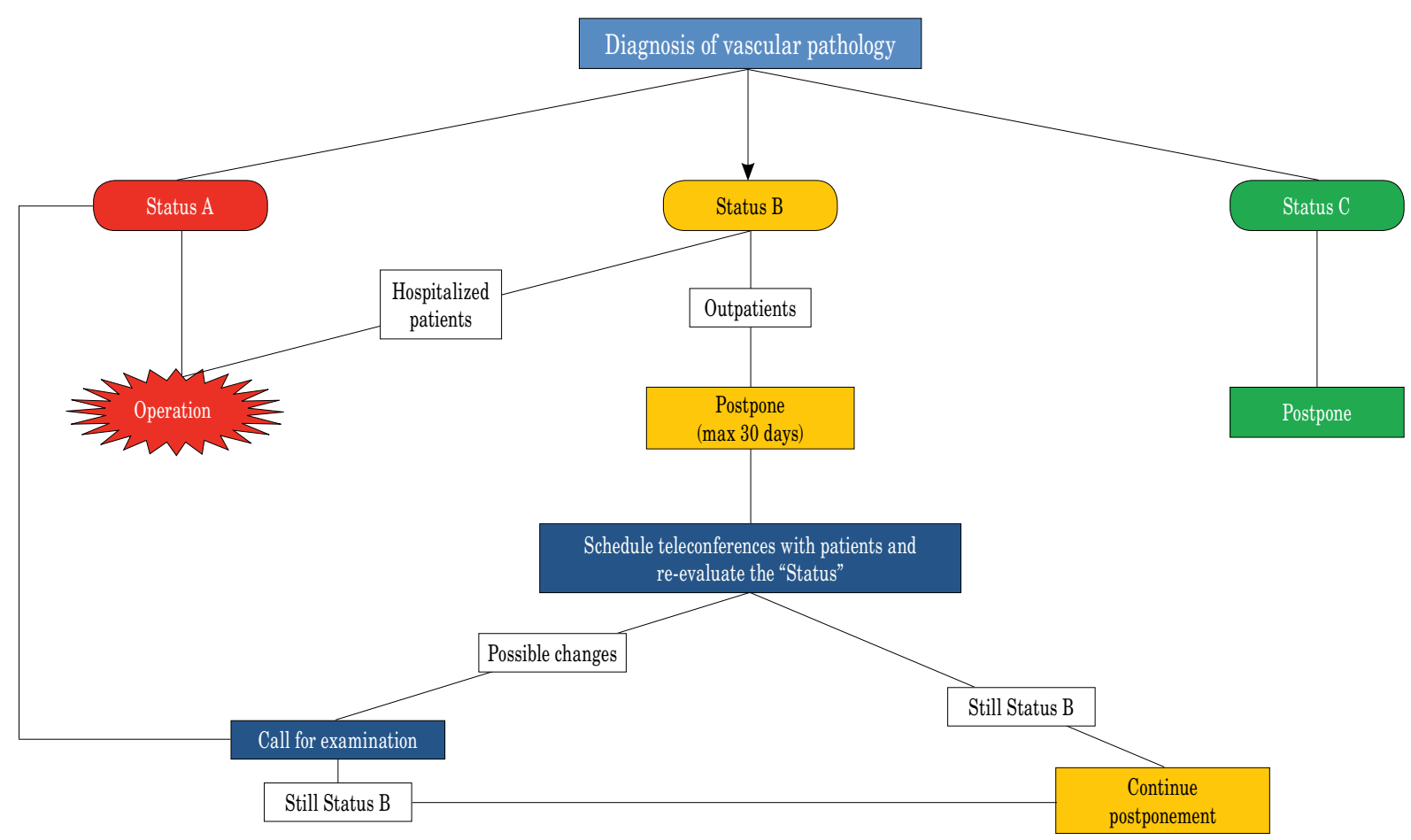

Figure 2. Treatment algorithm for patients with vascular pathologies. 


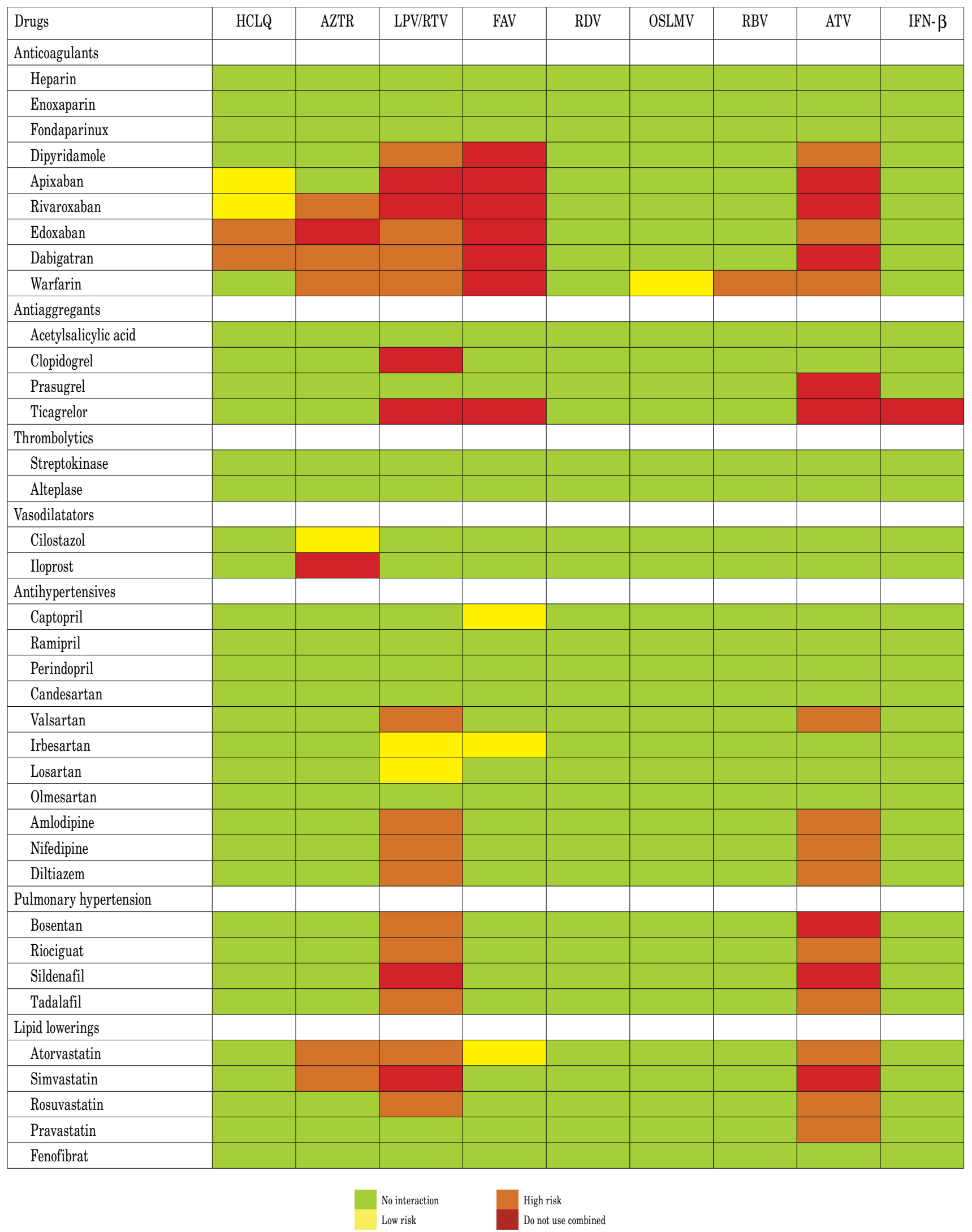

Figure 3. Drug-drug interactions.

HCLQ: Hydroxychloroquine; AZTR: Azithromycin; LPV/RTV: Lopinavir/ritonavir; FAV: Favipiravi; RDV: Remdesivir; OSLMV: 0seltamivir; RBV: Ribavirine; ATV: Atazanavir; IFN- $\beta$ : Interferon beta. 
an anesthesiologist, vascular surgeon, and infectious diseases specialist should decide and manage the follow-up schedule together. If the patient is intubated, extubation can be performed in the operation room to limit possible nosocomial transmission. As there are plenty of documented COVID-19 cases among healthcare providers, healthcare workers should follow the infection control policies precisely, until the COVID-19 patient is discharged. Of note, early discharge should be considered for the effective use of utilities of the healthcare facilities.

Furthermore, every outpatient scheduled to undergo surgery or an intervention due to a vascular emergency should be considered a possible COVID-19 patient. All perioperative preventive and precautionary measures must be also taken meticulously for this group of patients.

\section{Special considerations requiring attention during medical treatment of COVID-19 patients}

Coagulopathy in COVID-19 patients was confirmed in a multi-center, retrospective cohort study of 191 adults conducted by Zhou et al. ${ }^{[42]}$ In addition, it has long been recognized that activation of coagulation and/or fibrinolysis occurs as a part of the acute inflammatory response. It is recommended that physicians should be aware of these risks. During the perioperative period, each patient should be discussed separately before tailoring medical treatment. Baseline hemostatic system tests should be performed and coagulation or bleeding risk assessment should be carried out.

In conclusion, as we have been through extraordinary times, scientists have been making a great effort to develop specific agents for the treatment of COVID-19. Several drugs such as chloroquine, arbidol, remdesivir, and favipiravir are currently used for this purpose in the frontline institutes and some promising results have been achieved so far. ${ }^{[43-46]}$ During the pandemic, since the majority of patients are followed at home, a wellorganized medical therapy -best medical therapyhave gained more importance. While starting best medical therapy for patients with vascular disease (i.e., antiaggregants, anticoagulants, thrombolytics, vasodilators, antihypertensives, and statins) potential drug interactions should be taking into account. ${ }^{[47]}$ We summarized drugs, including most frequently used in best medical therapy for patients with vascular disease, and their interactions with agents used for COVID-19 treatment (Figure 3).

\section{Declaration of conflicting interests}

The authors declared no conflicts of interest with respect to the authorship and/or publication of this article.

\section{Funding}

The authors received no financial support for the research and/or authorship of this article.

\section{REFERENCES}

1. World Health Organization. WHO announces COVID19 outbreak a pandemic. Available at: http://www.euro. who.int/en/health-topics/health-emergencies/coronaviruscovid-19/news/news/2020/3/who-announces-covid-19outbreak-apandemic. [Accessed: April 02, 2020]

2. Aboyans V, Ricco JB, Bartelink MEL, Björck M, Brodmann M, Cohnert T, et al. Editor's Choice - 2017 ESC Guidelines on the Diagnosis and Treatment of Peripheral Arterial Diseases, in collaboration with the European Society for Vascular Surgery (ESVS). Eur J Vasc Endovasc Surg 2018;55:305-68.

3. Rooke TW, Hirsch AT, Misra S, Sidawy AN, Beckman JA, Findeiss L, et al. Management of patients with peripheral artery disease (compilation of 2005 and 2011 ACCF/AHA Guideline Recommendations): a report of the American College of Cardiology Foundation/American Heart Association Task Force on Practice Guidelines. J Am Coll Cardiol 2013;61:1555-70.

4. Lane R, Ellis B, Watson L, Leng GC. Exercise for intermittent claudication. Cochrane Database Syst Rev 2014:7:CD000990.

5. Mills JL Sr, Conte MS, Armstrong DG, Pomposelli FB, Schanzer A, Sidawy AN, et al. The Society for Vascular Surgery Lower Extremity Threatened Limb Classification System: risk stratification based on wound, ischemia, and foot infection (WIfI). J Vasc Surg 2014;59:220-34.

6. Rutherford RB, Baker JD, Ernst C, Johnston KW, Porter $\mathrm{JM}$, Ahn S, et al. Recommended standards for reports dealing with lower extremity ischemia: revised version. J Vasc Surg 1997;26:517-38.

7. McCready RA, Pairolero PC, Gilmore JC, Kazmier FJ, Cherry KJ Jr, Hollier LH. Isolated iliac artery aneurysms. Surgery 1983;93:688-93.

8. Wanhainen A, Verzini F, Van Herzeele I, Allaire E, Bown M, Cohnert T, et al. Editor's Choice-European Society for Vascular Surgery (ESVS) 2019 Clinical Practice Guidelines on the Management of Abdominal Aorto-iliac Artery Aneurysms. Eur J Vasc Endovasc Surg 2019;57:8-93.

9. Santilli SM, Wernsing SE, Lee ES. Expansion rates and outcomes for iliac artery aneurysms. J Vasc Surg 2000;31:114-21.

10. Sampson UK, Norman PE, Fowkes FG, Aboyans V, Yanna Song, Harrell FE Jr, et al. Global and regional burden of aortic dissection and aneurysms: mortality trends in 21 world regions, 1990 to 2010. Glob Heart 2014;9:171-80.

11. Sampson UK, Norman PE, Fowkes FG, Aboyans V, Song Y, Harrell FE Jr, et al. Estimation of global and regional incidence and prevalence of abdominal aortic aneurysms 1990 to 2010. Glob Heart 2014;9:159-70. 
12. Erbel R, Aboyans V, Boileau C, Bossone E, Bartolomeo RD, Eggebrecht H, et al. 2014 ESC Guidelines on the diagnosis and treatment of aortic diseases: Document covering acute and chronic aortic diseases of the thoracic and abdominal aorta of the adult. The Task Force for the Diagnosis and Treatment of Aortic Diseases of the European Society of Cardiology (ESC). Eur Heart J 2014;35:2873-926.

13. Bown MJ, Sweeting MJ, Brown LC, Powell JT, Thompson SG. Surveillance intervals for small abdominal aortic aneurysms: a meta-analysis. JAMA 2013;309:806-13.

14. Coady MA, Rizzo JA, Hammond GL, Mandapati D, Darr U, Kopf GS, et al. What is the appropriate size criterion for resection of thoracic aortic aneurysms? J Thorac Cardiovasc Surg 1997;113:476-91.

15. Johansson G, Markström U, Swedenborg J. Ruptured thoracic aortic aneurysms: a study of incidence and mortality rates. J Vasc Surg 1995;21:985-8.

16. Moro H, Hayashi J, Sogawa M. Surgical management of the ruptured aortic arch. Ann Thorac Surg 1999;67:593-4.

17. Weiss G, Wolner I, Folkmann S, Sodeck G, Schmidli J, Grabenwöger $\mathrm{M}$, et al. The location of the primary entry tear in acute type B aortic dissection affects early outcome. Eur J Cardiothorac Surg 2012;42:571-6.

18. Ganaha F, Miller DC, Sugimoto K, Do YS, Minamiguchi $\mathrm{H}$, Saito $\mathrm{H}$, et al. Prognosis of aortic intramural hematoma with and without penetrating atherosclerotic ulcer: a clinical and radiological analysis. Circulation 2002;106:342-8.

19. Schlösser FJ, Gusberg RJ, Dardik A, Lin PH, Verhagen HJ, Moll FL, et al. Aneurysm rupture after EVAR: can the ultimate failure be predicted? Eur J Vasc Endovasc Surg 2009;37:15-22.

20. Sidloff DA, Stather PW, Choke E, Bown MJ, Sayers RD. Type II endoleak after endovascular aneurysm repair. Br J Surg 2013;100:1262-70.

21. Hasse B, Husmann L, Zinkernagel A, Weber R, Lachat M, Mayer D. Vascular graft infections. Swiss Med Wkly 2013;143:w13754.

22. Samson RH, Veith FJ, Janko GS, Gupta SK, Scher LA. A modified classification and approach to the management of infections involving peripheral arterial prosthetic grafts. J Vasc Surg 1988;8:147-53.

23. Bonifati DM, Lorenzi A, Ermani M, Refatti F, Gremes E, Boninsegna $\mathrm{C}$, et al. Carotid stenosis as predictor of stroke after transient ischemic attacks. J Neurol Sci 2011;303:85-9.

24. Nordanstig A, Rosengren L, Strömberg S, Österberg K, Karlsson L, Bergström G, et al. Editor's Choice - Very Urgent Carotid Endarterectomy is Associated with an Increased Procedural Risk: The Carotid Alarm Study. Eur J Vasc Endovasc Surg 2017;54:278-86.

25. White RH. The epidemiology of venous thromboembolism. Circulation 2003;107:I4-8.

26. Oguzkurt L, Ozkan U, Demirturk OS, Gur S. Endovascular treatment of phlegmasia cerulea dolens with impending venous gangrene: manual aspiration thrombectomy as the first-line thrombus removal method. Cardiovasc Intervent Radiol 2011;34:1214-21.

27. Klok FA, Kruip MJHA, van der Meer NJM, Arbous MS, Gommers DAMPJ, Kant KM, et al. Incidence of thrombotic complications in critically ill ICU patients with COVID-19. Thromb Res 2020. pii: S0049-3848(20)301201. [Epub ahead of print]

28. Günertem E, Akay T, Aliyev A, Beyazpınar S, Erdil N, Erer D, et al. Treatment and prophylaxis strategies for deep vein thrombosis during COVID-19 outbreak. Turk J Vasc Surg 2020. [In Press]

29. Bergqvist D, Lindholm C, Nelzén O. Chronic leg ulcers: the impact of venous disease. J Vasc Surg 1999;29:752-5.

30. Schrag D, Hershman DL, Basch E. Oncology Practice During the COVID-19 Pandemic. JAMA 2020. [Epub ahead of print]

31. Gettman MT, Boelter CW, Cheville JC, Zincke H, Bryant SC, Blute ML. Charlson co-morbidity index as a predictor of outcome after surgery for renal cell carcinoma with renal vein, vena cava or right atrium extension. J Urol 2003;169:1282-6.

32. Available at: https://www.facs.org/covid-19/clinicalguidance/elective-case/vascular-surgery

33. Chaikof EL, Dalman RL, Eskandari MK, Jackson BM, Lee WA, Mansour MA, et al. The Society for Vascular Surgery practice guidelines on the care of patients with an abdominal aortic aneurysm. J Vasc Surg 2018;67:2-77.

34. Meissner MH, Gloviczki P, Comerota AJ, Dalsing MC, Eklof BG, Gillespie DLet al. Early thrombus removal strategies for acute deep venous thrombosis: clinical practice guidelines of the Society for Vascular Surgery and the American Venous Forum. J Vasc Surg 2012;55:1449-62.

35. Conte MS, Bradbury AW, Kolh P, White JV, Dick F, Fitridge R, et al. Corrigendum to 'Global Vascular Guidelines on the Management of Chronic LimbThreatening Ischemia' [European Journal of Vascular \& Endovascular Surgery 58/1S (2019) 1-109]. Eur J Vasc Endovasc Surg 2020;59:492-3.

36. Chen X, Liu Y, Gong Y, Guo X, Zuo M, Li J, et al. Perioperative Management of Patients Infected with the Novel Coronavirus: Recommendation from the Joint Task Force of the Chinese Society of Anesthesiology and the Chinese Association of Anesthesiologists. Anesthesiology 2020;132:1307-16.

37. Bozkurt K. Periferik Arter ve Ven Hastalıkları-Ulusal Tedavi Kılavuzu. 1. Baskı. İstanbul: Bayçınar Tibbi Yayınc1lık; 2016.

38. Zhang HF, Bo L, Lin Y, Li FX, Sun S, Lin HB, et al. Response of Chinese Anesthesiologists to the COVID-19 Outbreak. Anesthesiology 2020;132:1333-8.

39. Orser BA. Recommendations for Endotracheal Intubation of COVID-19 Patients. Anesth Analg 2020;130:1109-10.

40. Zou L, Ruan F, Huang M, Liang L, Huang H, Hong Z, et al. SARS-CoV-2 Viral Load in Upper Respiratory Specimens of Infected Patients. N Engl J Med 2020;382:1177-9.

41. Meng H, Xiong R, He R, Lin W, Hao B, Zhang L, et al. CT imaging and clinical course of asymptomatic cases with COVID-19 pneumonia at admission in Wuhan, China. J Infect 2020. pii: S0163-4453(20)30211-5. [Epub ahead of print]

42. Zhou F, Yu T, Du R, Fan G, Liu Y, Liu Z, et al. Clinical course and risk factors for mortality of adult inpatients with COVID-19 in Wuhan, China: a retrospective cohort study. 
Lancet 2020;395:1054-62.

43. Chan JF, Yao Y, Yeung ML, Deng W, Bao L, Jia L, et al. Treatment With Lopinavir/Ritonavir or Interferon$\beta 1 \mathrm{~b}$ Improves Outcome of MERS-CoV Infection in a Nonhuman Primate Model of Common Marmoset. J Infect Dis 2015;212:1904-13.

44. Kim UJ, Won EJ, Kee SJ, Jung SI, Jang HC. Combination therapy with lopinavir/ritonavir, ribavirin and interferon- $\alpha$ for Middle East respiratory syndrome. Antivir Ther 2016;21:455-9.

45. Wang Y, Fan G, Salam A, Horby P, Hayden FG, Chen C, et al. Comparative Effectiveness of Combined Favipiravir and Oseltamivir Therapy Versus Oseltamivir Monotherapy in Critically Ill Patients With Influenza Virus Infection.
J Infect Dis 2020;221:1688-98.

46. Gautret P, Lagier JC, Parola P, Hoang VT, Meddeb L, Mailhe M, et al. Hydroxychloroquine and azithromycin as a treatment of COVID-19: results of an open-label nonrandomized clinical trial. Int J Antimicrob Agents 2020. [Epub ahead of print]

47. Aktoz M, Altay H, Aslanger E, Atalar E, Aytekin V, Baykan AO, et al. Türk Kardiyoloji Derneği Uzlaş1 Raporu: COVID-19 Pandemisi ve Kardiyovasküler Hastalıklar Konusunda Bilinmesi Gerekenler (25 Mart 2020) [Consensus Report from Turkish Society of Cardiology: COVID-19 and Cardiovascular Diseases. What cardiologists should know. (25th March 2020)]. Turk Kardiyol Dern Ars 2020;48:1-48. 